\title{
Relationship between clamp force and pull-out strength in lag screw timber joints
}

\author{
Doppo Matsubara ${ }^{1}$ - Yoshiaki Wakashima ${ }^{2}$ Yasushi Fujisawa ${ }^{2} \cdot$ Hidemaru Shimizu $^{3}$. \\ Akihisa Kitamori ${ }^{4} \cdot$ Koichiro Ishikawa $^{5}$
}

Received: 8 May 2017/Accepted: 19 July 2017/Published online: 23 August 2017

(C) The Japan Wood Research Society 2017

\begin{abstract}
This study empirically examines the relationship between clamp force and pull-out strength in lag screw joints of timber members, using data obtained in tightening tests and pull-out tests. Maximum clamp force per unit screw length as determined from the tightening tests was lower than the lower bound for the $95 \%$ tolerance range for pull-out strength per unit screw length as determined from the pull-out tests. Moreover, X-ray CT (computed tomography) observations of anchor members from both tests revealed that failure behavior clearly differed between the tightening test and the pull-out test: tightening caused damage to the wooden, female thread in addition to major splitting damage in the wood perpendicular to the grain near the tip of the lag screw.
\end{abstract}

Keywords Lag screw joints · Clamp force · Pull-out strength · Tightening test

Part of this article was presented at the 67th Annual Meeting of the Japan Wood Research Society, Fukuoka, Japan, March 2017.

Doppo Matsubara

matsubara.doppo@iri-tokyo.jp

1 Tokyo Metropolitan Industrial Technology Research Institute, 2-4-10, Aomi, Koto-Ku, Tokyo 135-0064, Japan

2 Toyama Prefectural Agricultural, Forestry and Fisheries Research Center, 4940, Imizu, Toyama 939-0311, Japan

3 Sugiyama Jogakuen University, 17-3, Chikusa-ku, Nagoya, Aichi 464-8662, Japan

4 Research Institute for Sustainable Humanosphere, Kyoto University, Uji, Kyoto 611-0011, Japan

5 University of Fukui, 3-9-1, Fukui, Fukui 910-8507, Japan

\section{Introduction}

Lag screws which have benefits of minimal loosening and slippage during the initial application of loads are increasingly used to join timber members [1]. Construction management is an important component of ensuring lag screw joints are sufficiently strong, which require managers to exercise more caution than with bolt joints. For example, lag screws often cause wood cracking if screwed in without drilling a pilot hole, or driven in using a hammer [1]. These concerns are not limited to wood cracking: over-tightening lag screws may cause such joints to no longer perform at their true strength. Take for example the case of using a wrench to join a steel plate (or washer) to a timber member with a lag screw. Some of the force generated acts as a compressive force on the timber member, which generates an equivalent pull-out force on the lag screw. Tightening the lag screw until the pull-out force exceeds the wood's pull-out strength causes the axial force on the joint ("clamp force" below) to weaken, leading to poor adhesion between the two members. Among other construction managementrelated considerations, builders should ensure that lag screw joints are fastened with the proper amount of torque to prevent this from happening. To determine what constitutes "proper" torque, it is imperative to determine first the degree of clamp force caused by tightening a lag screw, and second how that clamp force relates to the pull-out strength of that screw. While many studies have been conducted on screw joints' pull-out strength, shear strength, and other mechanical properties [2-9], we can find none that regard the relationship between clamp force and pull-out force for lag screws. We are currently developing a high damping shear wall, in which the clamp force of lag screws in wood acts as a frictional resistance force between two timber members or between a timber member 
and a steel plate [10]. Controlling the clamp force is an important part of generating the frictional resistance in this project. We thus became interested in clarifying the relationship between clamp force and pull-out strength in lag screws, to investigate techniques for controlling the clamp force of lag screws.

In the present study, we empirically studied the relationship between clamp force and pull-out strength using experimental data collected from tightening tests and pullout tests. Our study also covers clamp force-related settings and considerations for preventing defects due to lag screw tightening.

\section{Materials and methods}

\section{Tightening tests of lag screw timber joints}

Lag screw joints were subjected to tightening tests according to the protocol in Matsubara et al. [11] using a bolt force tester (NST-500NM: Japan Instrumentation System Co., Ltd., Nara, Japan). Test specimens were composed of four parts: an attaching member, an anchor member, a round washer, and a lag screw (Fig. 1). Attaching and anchor members were created from three conifers: Cryptomeria japonica, Chamaecyparis obtusa, and Pseudotsuga menziesii. Figure 2 contains their dimensions: attaching members were $30 \times 45 \times 200 \mathrm{~mm}$ while anchor members were $60 \times 45 \times 60 \mathrm{~mm}$. Specimens were tested after sitting in the laboratory for approx. one month at $20 \pm 2{ }^{\circ} \mathrm{C}$. A bolt hole of $\varphi 13 \mathrm{~mm}$ was drilled in the attaching member; a pilot hole of $\varphi 7.5 \mathrm{~mm}$ and $55 \mathrm{~mm}$ deep was drilled in the anchor member. The curing room ranged from 32 to $43 \%$ humidity during the curing period (humidity was not strictly controlled). The density and moisture content of each specimen are shown in Table 1. To estimate the effect of washer sizes on clamp force and tightening angle, round washers of three dimensions were tested: $\varphi 30 \times 2.3 \mathrm{~mm}$ (diameter-thickness $\quad$ ratio $=13.0), \quad \varphi 32 \times 3.2 \mathrm{~mm} \quad(10.0), \quad$ and $\varphi 35 \times 4.5 \mathrm{~mm}$ (7.8). M12 lag screws were used, having a length of $180 \mathrm{~mm}$ and pitch diameter of $4.4 \mathrm{~mm}$. One is pictured in Fig. 3 along with detailed dimensions. During the tests, specimens were first set up in the testing device, and clamp force was measured by means of a load cell wedged between the attaching and anchor members. The tightening angle of the screw head was also measured. The screw was inserted along the wood perpendicular to the grain. The anchor member was held by a rotation-stopping component to limit any rotation due to tightening torque. Lag screws were tightened using a torque wrench until the screw head pressed against the round washer, i.e., until the axial force reached 10-30 N. Screws were tightened at a speed of $20 \mathrm{rpm}$ until a reduction in clamp force was observed, according to the protocol in [11]. Screws were fastened for an effective screw length (i.e., the distance the screw embeds in the anchor member; see Fig. 1) determined prior to testing: $42.7 \mathrm{~mm}$ for specimens with $\varphi 30 \times 2.3 \mathrm{~mm}$ washers, $41.8 \mathrm{~mm}$ for specimens with $\varphi 32 \times 3.2 \mathrm{~mm}$ washers, and $40.5 \mathrm{~mm}$ for specimens with $\varphi 35 \times 4.5 \mathrm{~mm}$ washers. Six specimens were tested in each condition.

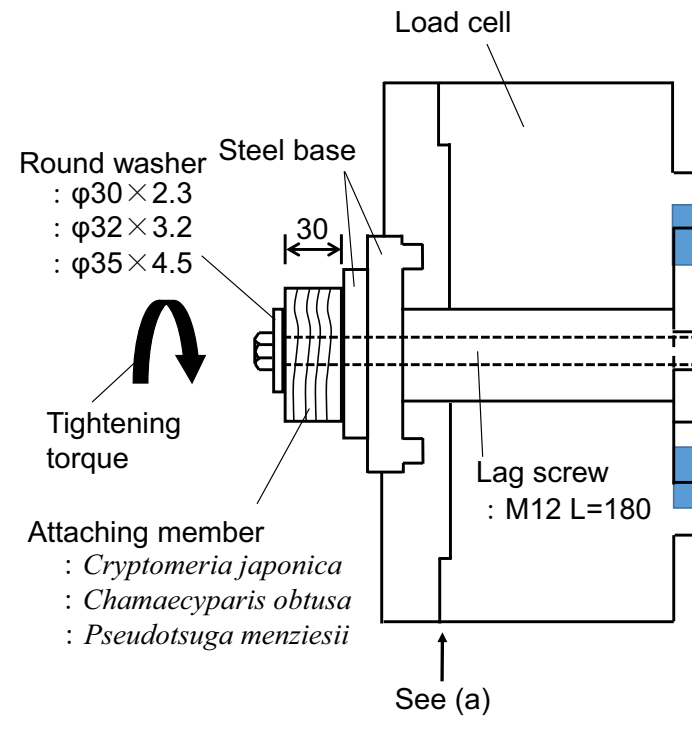

(UNIT : mm)

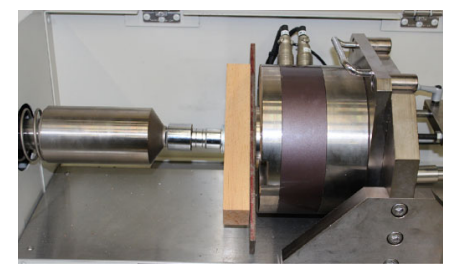

(a)

$\overleftarrow{\text { See }}(\mathrm{b})$

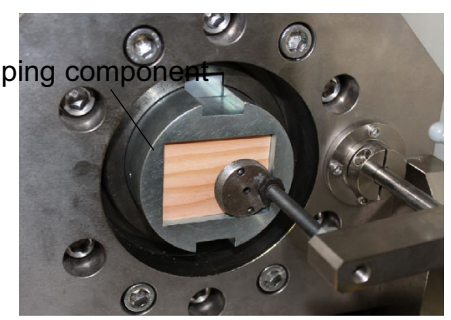

(b)

Fig. 1 Tightening test method for lag screw timber joints. Reference mark the initial screw length $=42.7 \mathrm{~mm}$ for $\varphi 30 \times 2.3 \mathrm{~mm}$ washers; $41.8 \mathrm{~mm}$ for $\varphi 32 \times 3.2 \mathrm{~mm}$ washers; $40.5 \mathrm{~mm}$ for $\varphi 35 \times 4.5 \mathrm{~mm}$ washers 


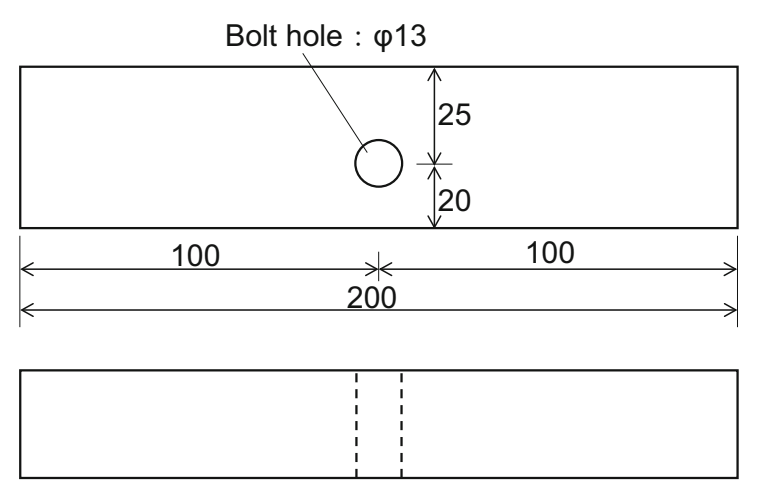

(a) Attaching member
Pilot hole : $\varphi 7.5$
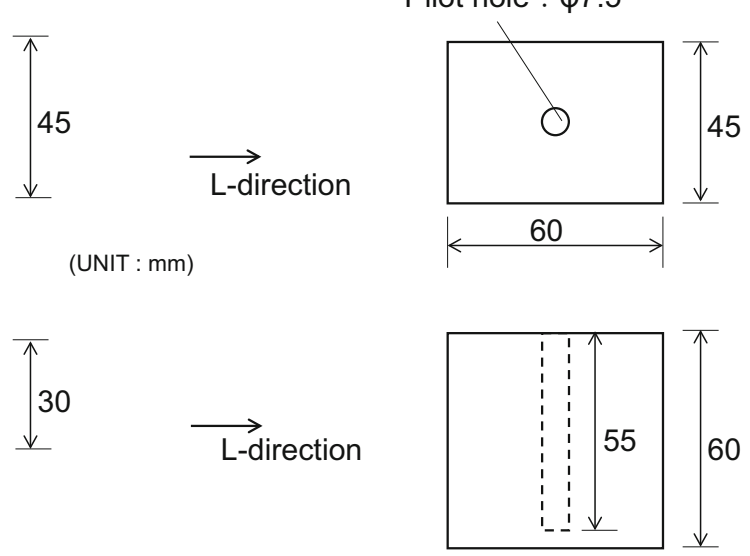

(b) Anchor member

Fig. 2 Dimensions of attaching member and anchor member

Table 1 Basic properties of test materials

\begin{tabular}{llll}
\hline Conifer species & Member & Density $\left(\mathrm{kg} / \mathrm{m}^{3}\right)$ & Moisture content $(\%)$ \\
\hline Cryptomeria japonica & Attaching member & & \\
& Ave. & 312 & 9.8 \\
& SD & 15.4 & 0.7 \\
& Anchor member & & \\
& Ave. & 353 & 9.0 \\
& SD & 7.3 & 0.4 \\
Chamaecyparis obtusa & Attaching member & & \\
& Ave. & 423 & 9.3 \\
& SD & 20.6 & 1.2 \\
& Anchor member & & 8.7 \\
& Ave. & 429 & 0.6 \\
Pseudotsuga menziesii & SD & 8.2 & \\
& Attaching member & & 8.5 \\
& Ave. & 572 & 1.0 \\
& SD & 70.2 & 8.7 \\
& Anchor member & 661 & 0.7
\end{tabular}

Ave. average, $S D$ standard deviation

\section{Pull-out tests of lag screw timber joints}

Lag screw pull-out tests were performed using leftover anchor member from the tightening tests. The anchor members tested were made from the same three tree species. Figure 4 shows the experimental method. Specimen dimensions, pilot hole diameter, and screw-insertion direction were identical to the tightening tests. Wood density and moisture content were within the ranges indicated in Table 1. First, a screw was inserted into an anchor member fixed by the rotation-stopping component to a target screw length of $46 \mathrm{~mm}$ [here, $45.0-49.0 \mathrm{~mm}$ (measured screw length)] using a torque wrench. Pull-out tests were conducted at a test speed of $88 \mathrm{~mm} / \mathrm{min}$ (=tightening speed $20 \mathrm{rpm} \times$ pitch diameter of $4.4 \mathrm{~mm}$ ) using a universal tester (AG-100kNX Plus: Shimadzu Corp., Kyoto, Japan). Load was measured over a single stroke. Six specimens were tested in each condition.

\section{X-ray CT (computed tomography) scanning}

Failure behavior following the tightening test and pull-out test was observed in each anchor member using an X-ray CT scanner (SkyScan2211, Bruker, Kontich, Belgium). 


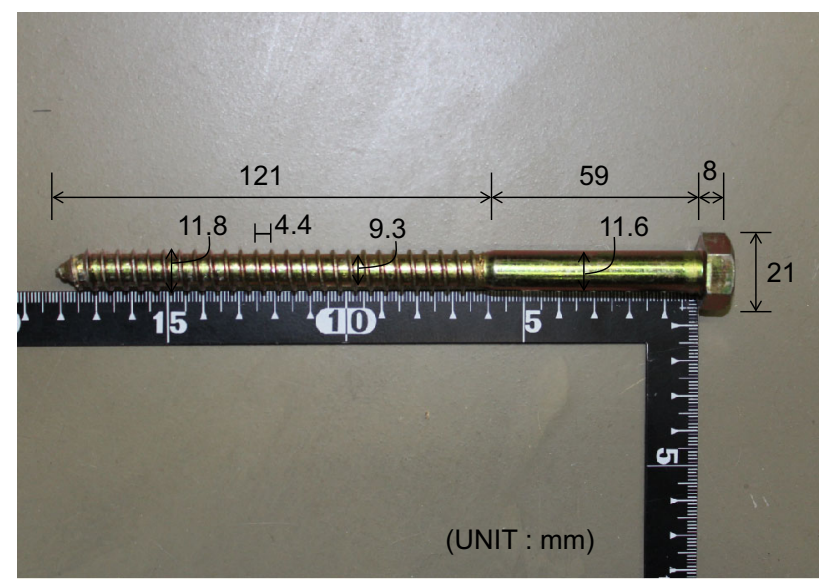

Fig. 3 Detailed dimensions of lag screw

Specimens were imaged using a flat-panel X-ray detector at a tube voltage of $50 \mathrm{kV}$ and tube current of $320 \mu \mathrm{A}$.

\section{Results and discussion}

\section{Relationship between clamp force and tightening angle}

Figure 5 shows the relationship between clamp force and tightening angle obtained in the tightening tests for a representative specimen of each tree species. As tightening angle increases, clamp force continues to rise even after some initial yielding, but decreases after reaching a maximum value. Figure 6 shows the relationship between washer diameter-thickness ratio and maximum clamp force. Significant variation in clamp force due to diameterthickness ratio is not visible for $C$. japonica members. However, C. obtusa and P. menziesii members exhibit higher maximum clamp force at larger diameter-thickness ratios. In addition, Fig. 5 shows that larger diameterthickness ratios result in the maximum clamp force being reached at larger tightening angles. We next investigated the relationship between maximum tightening angle in the maximum clamp force and the initial elasticity gradient $\left(\mathrm{kN} /{ }^{\circ}\right)$ based on the relationship between clamp force and tightening angle. Initial elasticity gradient was determined separately for each specimen by calculating the slope of the elasticity gradient using the method of least squares over the interval it appeared linear. Maximum tightening angle was determined by subtracting the $x$-intersect of the elasticity gradient from tightening angle. Figure 7 shows the relationship between washer diameter-thickness ratio and maximum tightening angle. Maximum tightening angle seems to increase with increasing diameter-thickness ratio for $C$. japonica, C. obtusa, and P. menziesii specimens. Figure 8 shows the relationship between initial elasticity gradient and maximum tightening angle. Although there is a rather large dispersion, maximum tightening angle tends to decrease with increasing initial elasticity gradient. Where embedment traces of round washer on attaching member were confirmed visually in all specimens, this finding can be attributed to the washer exhibiting higher embedment stiffness at smaller diameter-thickness ratios [12].

\section{Comparison of pull-out strength and maximum clamp force}

Figure 9 shows the representative load-displacement profiles obtained in the pull-out tests for a single test stroke, while Table 2 shows an overview of pull-out strength. Pullout strength is defined in this study as the maximum load
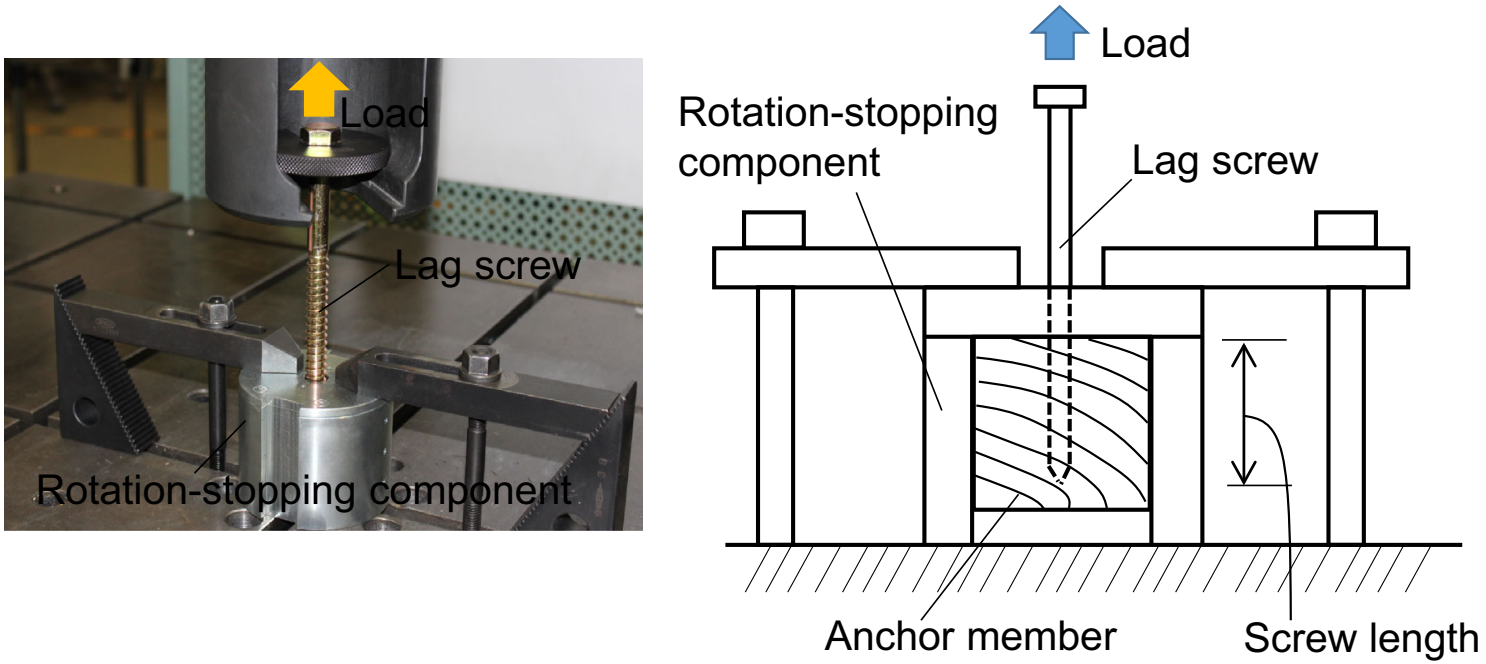

Fig. 4 Pull-out test method for lag screw timber joints 

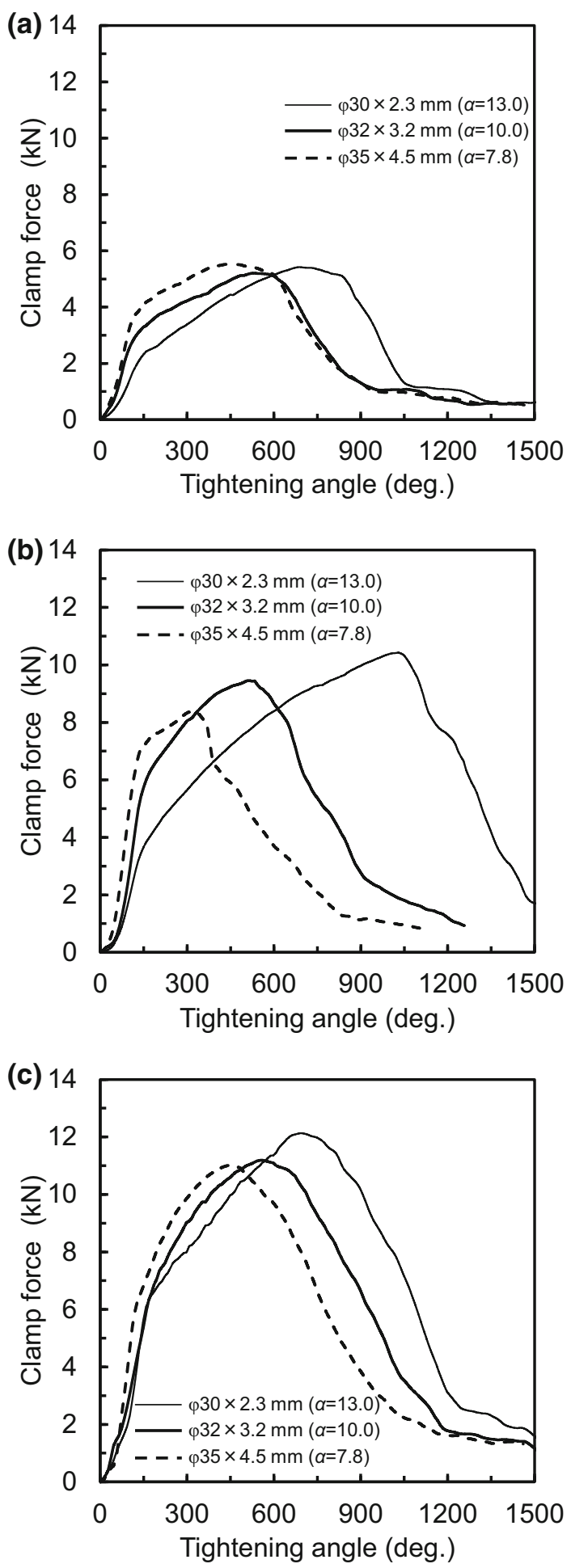

Fig. 5 Relationship between clamp force and tightening angle. a Cryptomeria japonica, b Chamaecyparis obtusa, c Pseudotsuga menziesii and $\alpha$ diameter-thickness ratio of round washer

observed in the pull-out test. The table contains values for $P_{\max -\mathrm{L}}(\mathrm{kN} / \mathrm{mm})$ and $P_{5 \% \text {-pull }}(\mathrm{kN} / \mathrm{mm})$ : these measures, respectively, indicate pull-out strength per unit screw
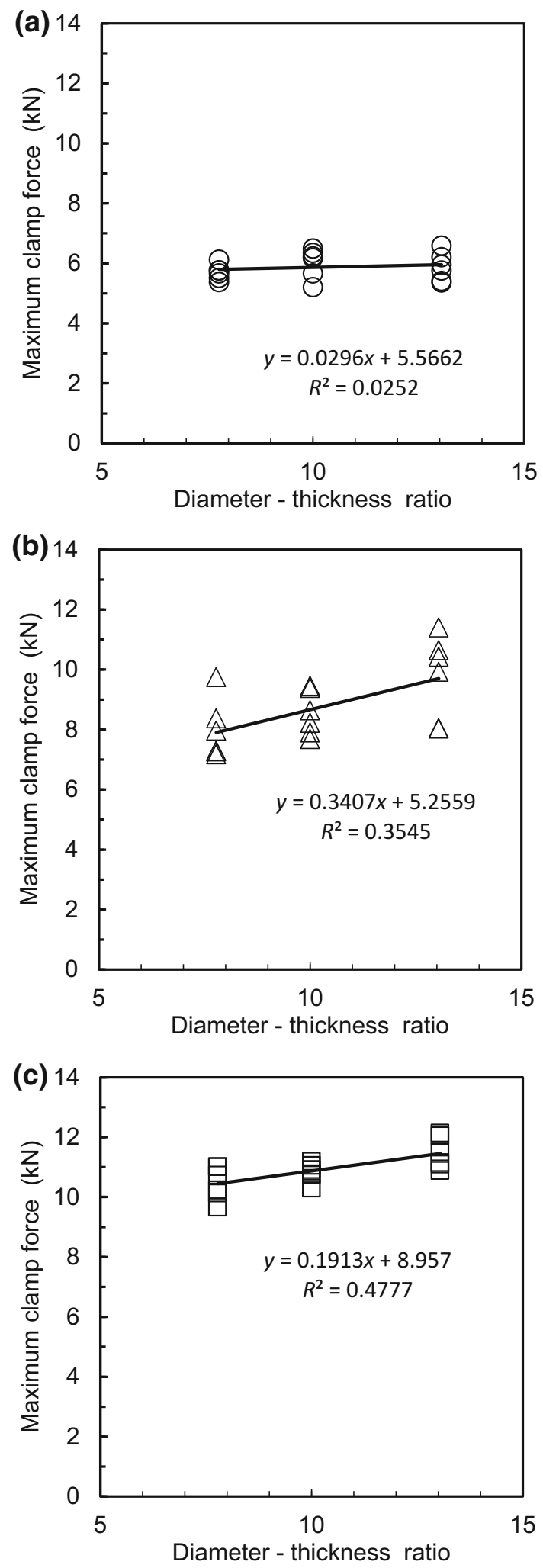

Fig. 6 Relationship between maximum clamp force and diameterthickness ratio of round washer. a Cryptomeria japonica, b Chamaecyparis obtusa, and c Pseudotsuga menziesii 

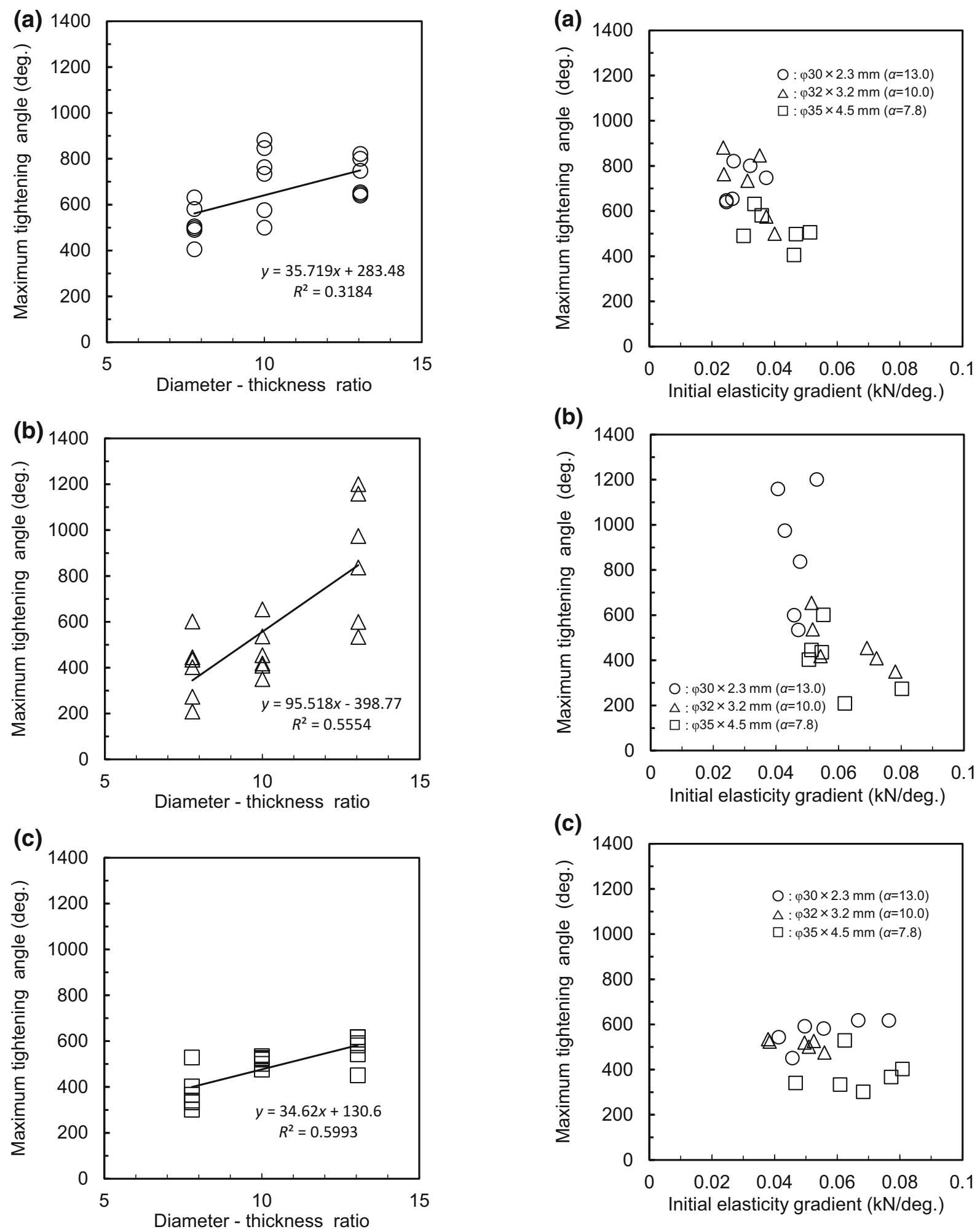

Fig. 7 Relationship between maximum tightening angle and diameter-thickness ratio of round washer. a Cryptomeria japonica, b Chamaecyparis obtusa, and c Pseudotsuga menziesii

Fig. 8 Relationship between maximum tightening angle and initial elasticity gradient. a Cryptomeria japonica, b Chamaecyparis obtusa, c Pseudotsuga menziesii, and $\alpha$ diameter-thickness ratio of round washer 


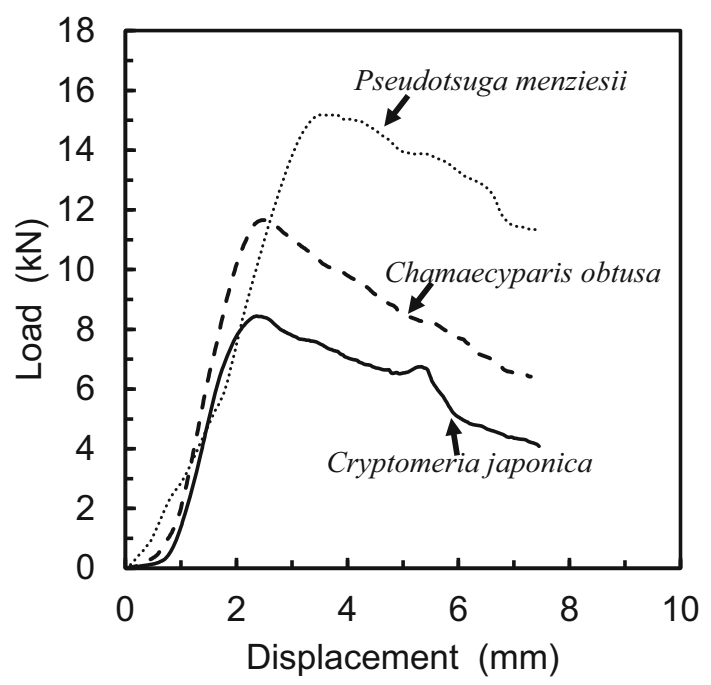

Fig. 9 Load-displacement relationship obtained in pull-out tests

Table 2 Results of pull-out tests

\begin{tabular}{lcll}
\hline Conifer species & \multicolumn{1}{l}{$P_{\max }(\mathrm{kN})$} & $P_{\text {max-L }}(\mathrm{kN} / \mathrm{mm})$ & $P_{5 \%-\mathrm{pull}}(\mathrm{kN} / \mathrm{mm})$ \\
\hline \multicolumn{2}{l}{ Cryptomeria japonica } & & \\
Max. & 9.12 & 0.198 & 0.142 \\
Min. & 7.52 & 0.159 & \\
Ave. & 8.32 & 0.179 & \\
SD & 0.67 & 0.016 & \\
Chamaecyparis & obtusa & & \\
Max. & 11.83 & 0.252 & \\
Min. & 9.92 & 0.216 & \\
Ave. & 11.13 & 0.239 & \\
SD & 0.81 & 0.015 & \\
Pseudotsuga & menziesii & & \\
Max. & 16.53 & 0.329 & \\
Min. & 13.37 & 0.294 & \\
Ave. & 14.93 & 0.312 & \\
SD & 1.03 & 0.017 & \\
\hline
\end{tabular}

$P_{\text {max }}$ pull-out strength, $P_{\max -L}$ pull-out strength per unit screw length, $P_{5 \% \text {-pull }} 5 \%$ lower limit value of pull-out strength per unit screw length, Max. maximum, Min minimum, Ave. average, $S D$ standard deviation

length and the lower bound for the $95 \%$ tolerance range for pull-out strength per unit screw length (confidence level $=75 \%$ ) [13]. Figure 9 and Table 2 both indicate that $P_{\max }, P_{\max -\mathrm{L}}$, and $P_{5 \% \text {-pull }}$ were highest in $P$. menzeisii, followed by $C$. obtusa and $C$. japonica. Next, the maximum clamp force obtained in the tightening tests was converted into maximum clamp force per unit screw length $\left(F_{\mathrm{L}}: \mathrm{kN} / \mathrm{mm}\right)$. The relationship between $F_{\mathrm{L}}$ and $P_{5 \% \text {-pull }}$ was then examined. Figure 10 shows the relationship between washer diameter-thickness ratio and $F_{\mathrm{L}} / P_{5 \% \text {-pull }}$.
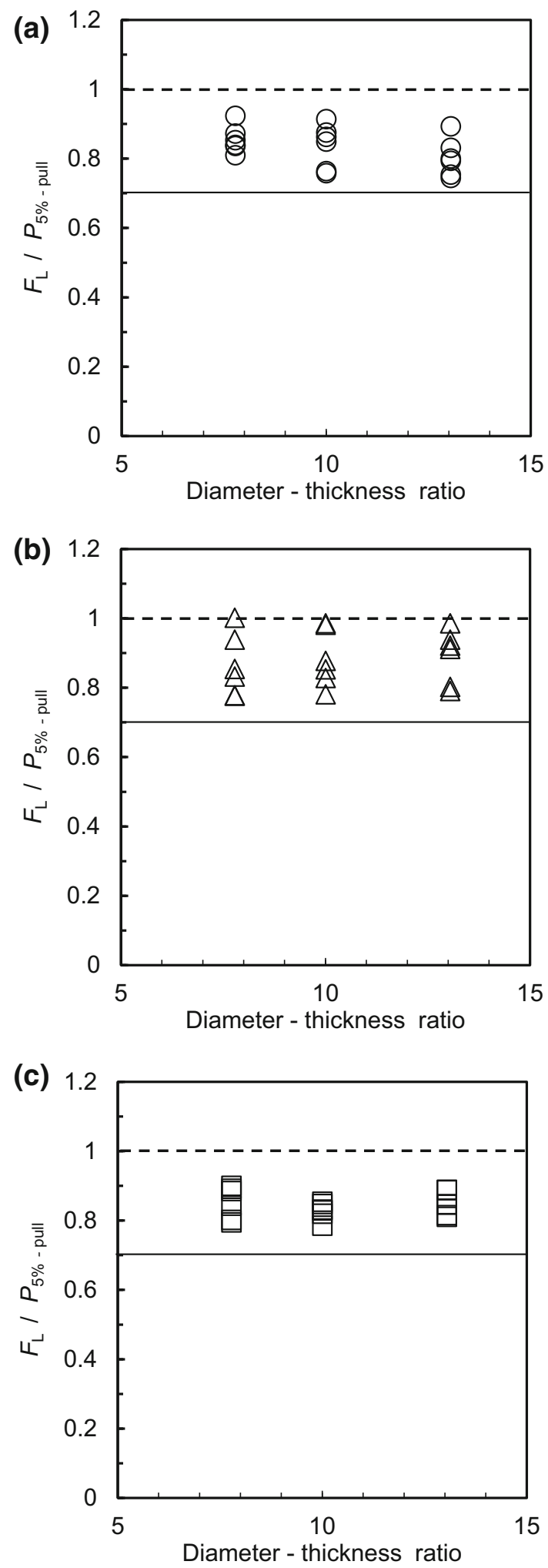

Fig. 10 Relationship between $F_{\mathrm{L}} / P_{5 \% \text {-pull }}$ and diameter-thickness ratio of round washer. a Cryptomeria japonica, b Chamaecyparis obtusa, c Pseudotsuga menziesii, $F_{\mathrm{L}}$ : maximum clamp force per unit screw length, and $P_{5 \% \text {-pull }}$ : 5\% lower limit value of pull-out strength per unit screw length 
Fig. 11 X-ray CT-scan images of typical failures of anchor members observed after the tightening and pull-out tests

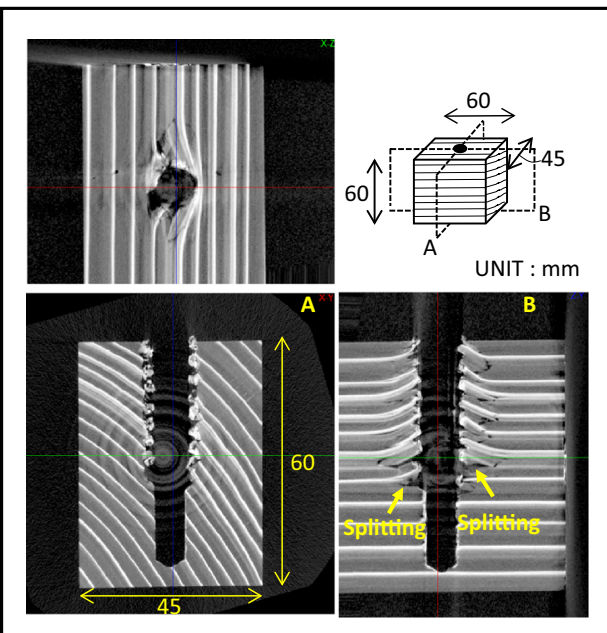

(a) Pull-out

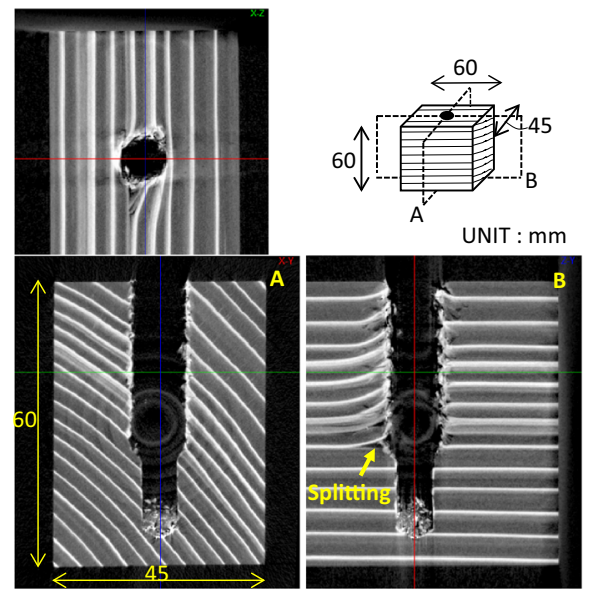

(b) Tightening

-Cryptomeria japonica-

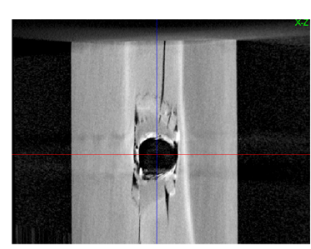

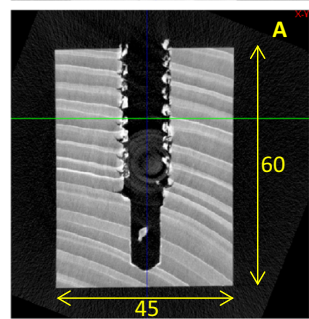

(a) Pull-out
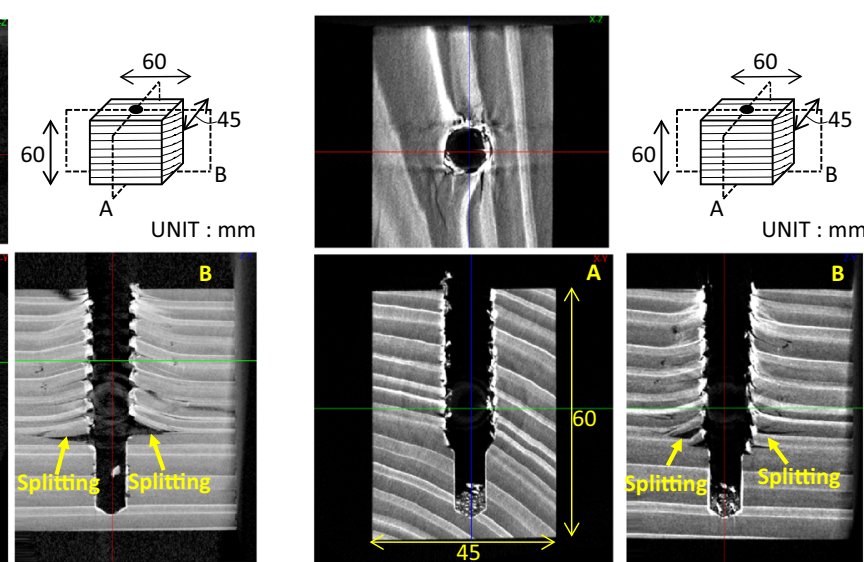

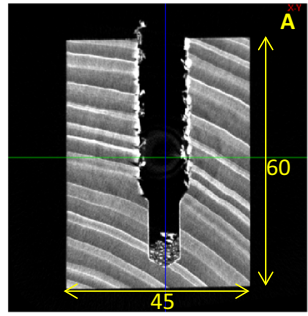

(b) Tightening

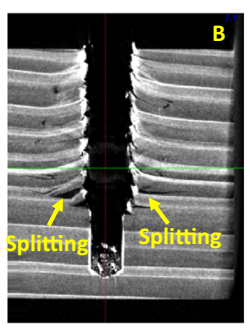

-Chamaecyparis obtusa-
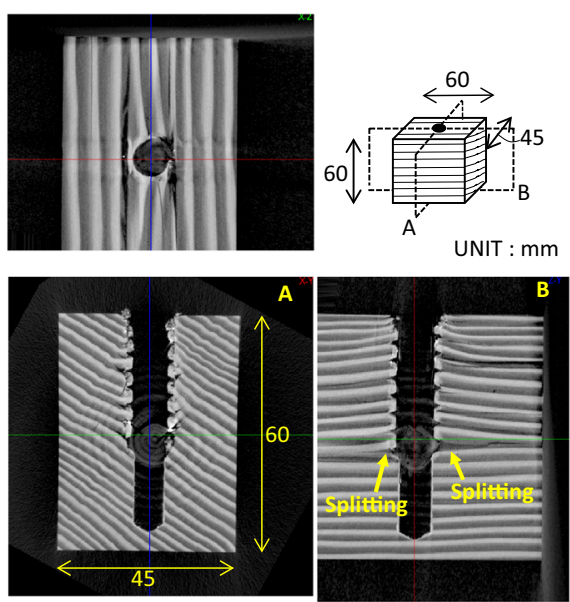

(a) Pull-out
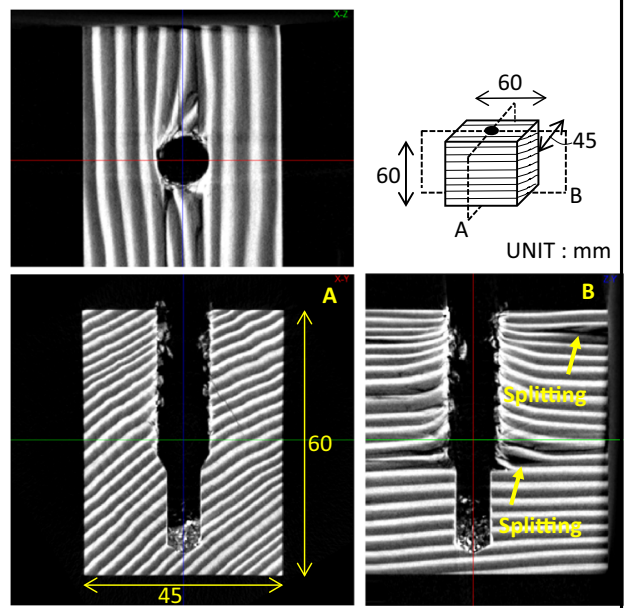

(b) Tightening

-Pseudotsuga menziesii- 
Here, the screw length in tightening for $F_{\mathrm{L}}$ was calculated according to the following equation:

$L_{\text {screw }}=L_{\text {init. }}+\frac{P \theta_{\max }}{360}$,

where $L_{\text {screw }}$ is screw length in tightening, $L_{\text {init. }}$ is initial screw length prior to tightening test (as described in Fig. 1), $P$ is screw pitch $(4.4 \mathrm{~mm})$, and $\theta_{\max }$ is maximum tightening angle calculated as described above. Strictly speaking, a lag screw expands when tightened, altering its pitch. We estimated the maximum expansion factors for the lag screw having the highest recorded maximum clamp force among all 54 specimens $(\sim 12 \mathrm{kN})$ based on screw length, cross-sectional area, and elastic Young's modulus. As the value measured was only in the order of $0.09 \%$, Eq. (1) simplifies this consideration by assuming a constant screw pitch. In addition, Eq. (1) is simplified by neglecting the deformation between the thread of the lag screw and the wood. No obvious trends were observed in the relationship between washer diameter-thickness ratio and $F_{\mathrm{L}} / P_{5 \% \text {-pull }}$ for any of the tree species. Generally speaking, however, $F_{\mathrm{L}}$ shrunk more than $P_{5 \% \text {-pull }}$, with $C$. japonica, C. obtusa, and $P$. menzeisii having respective average and minimum $F_{\mathrm{L}} / P_{5 \% \text {-pull }}$ ratios of 0.83 and $0.74,0.88$ and 0.78 , and 0.84 and 0.78. Figure 11 shows X-ray CT images of anchor members after the tightening (in $\varphi 35 \times 4.5 \mathrm{~mm}$ ) and pullout tests. The images depict the damage sustained by anchor members in the tightening and pull-out tests. Major splitting damage was observed in the wood perpendicular to the grain near the tip of the lag screw in $C$. japonica, C. obtusa, and $P$. menzeisii specimens. The female grooves that formed in the wood are relatively distinct, but some deformation behavior is visible in wooden ridges between the grooves, which have warped upward in the direction of the pull-out force. In comparison, significant splitting damage, similar to that sustained in the pull-out tests, was observed in each tree species following the tightening tests. However, the wooden grooves were lost in all tree species, failure behavior that clearly differed from that seen after the pull-out tests. We can consider these differences in failure behavior in combination with $F_{\mathrm{L}}$ being smaller than $P_{5 \% \text {-pull. }}$. Mechanical resistance on a lag screw is attributable to the compressive resistance placed on the screw thread along a joint's axis by the surrounding wood [14]. When the lag screw is tightened, however, shear resistance generated from tightening torque are generated in addition to this compressive resistance. We can thus suppose that these composite mechanical elements result in the destruction of the wooden internal thread, and accordingly a smaller $F_{\mathrm{L}}$ than $P_{5 \% \text {-pull }}$.

In summary, tightening resulted in a smaller maximum clamp force than the pull-out force observed in the pull-out test, and failure behavior in anchor members clearly differed between the pull-out tests and the tightening tests. When assessing maximum clamp force, it appears necessary to multiply $P_{5 \% \text {-pull }}$ by a reduction coefficient of some magnitude to prevent damage to anchor members due to tightening. We propose a value of 0.7 for this coefficient, as $F_{\mathrm{L}}$ is approximately $70 \%$ of $P_{5 \% \text {-pull when calculated for }}$ all specimens tested in this study (see Fig. 10).

\section{Conclusions}

We performed tightening tests and pull-out tests on lag screw joints, and investigated the relationship between clamp force and pull-out strength data obtained in the experiments. Joints consisted of two timber members of three tree species (C. japonica, C. obtusa, and P. menzeisii), M12 lag screws, and round washers of three sizes $(\varphi 30 \times 2.3, \varphi 32 \times 3.2$, and $\varphi 35 \times 4.5 \mathrm{~mm})$. Our findings are as follows:

1) In the tightening tests, maximum tightening angle increased with increasing washer diameter-thickness ratio, and maximum tightening angle decreased with increasing initial elasticity gradient.

2) In the pull-out tests, P. menzeisii had the highest pullout strength, followed by $C$. obtusa and $C$. japonica.

3) Maximum clamp force per unit screw length $\left(F_{\mathrm{L}}\right)$ was lower than the lower bound for the 95\% tolerance range for pull-out strength per unit screw length $\left(P_{5 \% \text {-pull }}\right)$. Their ratio $\left(F_{\mathrm{L}} / P_{5 \% \text {-pull }}\right)$ had respective average and minimum values of 0.83 and 0.74 for C. japonica specimens, 0.88 and 0.78 for C. obtusa, and 0.84 and 0.78 for P. menzeisii specimens.

4) X-ray CT observations of anchor members following the tightening and pull-out tests revealed that failure behavior clearly differed between the two tests: tightening caused damage to the wooden, female thread in addition to major splitting damage in the wood perpendicular to the grain near the tip of the lag screw.

The findings above reveal that tightening the lag screw in a lag screw joint between timber members results in a smaller maximum clamp force than the pull-out strength for the same joint. They suggest the necessity of taking their relationship into account when deciding on a clamp force for tightening steps to prevent damage to the anchor member.

Acknowledgements This work was supported in part by the Science and Technology Research Promotion Program for Agriculture, Forestry, Fisheries and Food Industry. 


\section{References}

1. Japan Timber Engineering Society (2012) ISBN:978-4-75301856-7 C3052. Inoue-shoin Co. Ltd., Tokyo, pp 173-175

2. Tokuda M, Hirashima Y, Matsubara H (1989) The strength of lag-screw joints I. Lateral strength parallel to the grain (in Japanese). Mokuzai Gakkaishi 35(6):473-481

3. Tokuda M, Hirashima Y, Matsubara H (1989) The strength of lag-screw joints II. Lateral strength perpendicular to the grain (in Japanese). Mokuzai Gakkaishi 35(6):482-488

4. McLain TE (1997) Design axial withdrawal strength from wood I. Wood screws and lag screws. Forest Prod J 47(5):77-84

5. Pirnbacher G, Brandner R, Schickhofer G (2009) Base parameters of self-tapping screws. In: Proceedings, CIB-W18, Dubendorf, paper 42-7-1

6. Frese M, Blass HJ (2009) Models for the calculation of the withdrawal capacity of self-tapping screws. In: Proceedings, CIBW18, Dubendorf, paper 42-7-3

7. Graham DA, Carradine DM, Bender DA, Dolan JD (2010) Monotonic and reverse-cyclic loading of lag screw connections for $\log$ shear wall construction. J Matelials in Civil Eng 22(1):88-95

8. Kobayashi K, Yasumura M (2013) Influences of number and spacing of fasteners on single shearing properties of steel-to- timber joints with lag screws (in Japanese). Kozo Kogaku Ronbunshu B 59B:537-543

9. Yeh MC, Lin YL, Huang GP (2014) Investigation of the structural performance of glulam beam connections using self-tapping screws. J Wood Sci 60(1):39-48

10. Wakashima Y, Shimizu H, Fujisawa Y, Ishikawa K, Kitamori A, Matsubara D (2016) High damping shear walls using wood friction joints. In: Proceeding of world conference on timber engineering, Vienna, Austria

11. Matsubara D, Nakano T, Shimada M, Funada R, Hattori N (2015) Effect of tightening velocity on the torque coefficient of timber jointing with bolts (in Japanese). Mokuzai Gakkaishi 61(1):33-39

12. Matsubara D, Shimada M, Hirai T, Funada R, Hattori N (2016) Embedment of metal washers into timber members of bolted timber joints I. Application of the theory of a beam on an elastic foundation (in Japanese). Mokuzai Gakkaishi 62(4):119-132

13. Architectural Institute of Japan (2006) Standard for structural design of timber structures (in Japanese). Architectural Institute of japan, Tokyo, pp 373-375

14. Murakami S, Jung K, Nakatani M, Kitamori A, Komatsu K (2010) Study on the pull-out performance of the screw type fasteners (in Japanese). In: Summaries of technical papers, annual meeting of the Architectural Institute of Japan: structure system, pp $189-190$ 